\title{
EFEKTIVITAS MODEL PEMBELAJARAN CONCEPT ATTAINMENT UNTUK MENINGKATKAN HASIL BELAJAR PADA MATA KULIAH STUDI KEISLAMAN DI PAI UNIPDU JOMBANG
}

\author{
Arifin \\ Aina'ul Mardliyah \\ M. Yahya Ashari \\ Ali Muhsin \\ Fakultas Agama Islam, Universitas Pesantren (UNIPDU) Jombang \\ Email: arifin2.unipdu@gmail.com
}

\begin{abstract}
This study aims to describe the effectiveness of learning Islamic Studies oriented Concept Learning Learning Model in terms of several aspects as follows: 1) The activities of students while participating in learning Islamic Studies oriented Learning Concept Concept Attainment Model; 2) Students' responses to Islamic learning activities oriented to Concept Attainment Learning Model Learning; 3) Learning Outcomes of students towards learning activities oriented Islamic Studies Learning Model Concept Attainment; 4) Barriers or constraints faced during the learning process of Islamic Studies oriented at Concept Learning Model attainment. In this study, subjects were taken from students of 6th Semester PAI Unipdu Jombang. The researcher is a lecturer in Islamic Studies in PAI 6th Semester class interested in conducting research especially in the class because of the heterogeneity of the class and it appears from the attitudes of students in learning quite diverse. Data collection is done by means of tests and interviews. Furthermore, to test the credibility of the data, time triangulation is performed. At different times tests are given and interviews with problems are equivalent to previous tests. Therefore, the authors conducted research to determine the learning outcomes of students in using the Concept Attainment Learning Model. This research uses "one group pretestposttest design". Data were collected using tests, and analyzed with descriptive statistical analysis.
\end{abstract}

Keyword: Concept Attainment Model, Islamic Study, Learning Outcomes.

\section{PENDAHULUAN}

Mata kuliah Studi keislaman di mata peserta didik PAI UNIPDU Jombang adalah salah satu mata kuliah yang membosankan. Hal ini merupakan tantangan bagi dosen PAI untuk mencari solusi bagaimana kegiatan pembelajaran menjadi bermakna dan menyenangkan serta tidak membosankan bagi peserta didik. PAI UNIPDU Jombang adalah program studi yang masih berkembang dalam Fakultas Agama Islam Unipdu Jombang, banyak tantangan dan kendala yang dihadapi untuk 
mempertahankan mutu akademik maupun non akademik. Hasil penelitian tentang Model Pembelajaran Concept attainment sampai sekarang ini telah banyak dilakukan tetapi hanya terbatas dilakukan pada SMP dan SMA.

Kesulitannya terletak pada proses melatihkan keterampilan agumentasi, keterampilan berpikir tingkat tinggi, dan keterampilan pemecahan masalah ${ }^{1}$, sehingga jarang sekali penelitian tentang pembelajaran Studi Keislaman dengan menggunakan Model Pembelajaran Concept attainment ${ }^{2}$ dilakukan pada peserta didik. Tetapi segala sesuatu dapat diberikan pada siapapun asal dengan cara yang benar. Begitu juga dengan pembelajaran Studi Keislaman dengan menggunakan Model Pembelajaran Concept attainment dapat digunakan dalam kegiatan belajar mengajar pada peserta didik asal digunakan dengan benar, disesuaikan dengan kebutuhan dan tingkat perkembangan peserta didik di perpendidikan tinggi. ${ }^{3}$

Peneliti adalah Tim dosen Pendidikan Agama Islam, yang tertarik untuk melakukan penelitian pengembangan pembelajaran Studi Keislaman khususnya di kelas PAI Semester 6. Pembelajaran Studi Keislaman cukup sulit dilakukan untuk peserta didik Tetapi jika permasalahan sehari-hari dapat dikaitkan dengan konsep atau prinsip yang ada dalam pembelajaran, maka peserta didik akan dapat menemukan konsep secara mandiri dan terstruktur tersebut melalui pembelajaran Studi Keislaman dengan menggunakan Model Pembelajaran Concept attainment.

Berdasarkan observasi awal yang dilakukan peneliti ditemukan beberapa permasalahan dalam pembelajaran Studi Keislaman di kelas PAI , antara lain:

1. Diperlukan metode, dan model pembelajaran yang tepat untuk menumbuhkan minat dan aktivitas peserta didik.

2. Kemampuan pemahaman konsep masih rendah

3. Aktivitas individu maupun kelompok belum terlihat maksimal, masih banyak peserta didik yang lebih banyak diam dan kurang aktif.

4. Hasil belajar pada UTS sebelumnya rendah, peserta didik yang mampu mencapai hanya $34 \%$ keberhasilan.

${ }^{1}$ Putra, M. I. S., Widodo, W. and Jatmiko, B., The Development of Guided Inquiry Science Learning Materials to Improve Science Literacy Skill of Prospective MI Teacher. Jurnal Pendidikan IPA Indonesia, JPII 5 (1) (2016) 83-93

${ }^{2}$ Wenno, I.H., Wattimena, P., Maspaitela, L., Comparative Study between Drill Skill and Concept Attainment Model towards Physics Learning Achievement. International Journal of Evaluation and Research in Education (IJERE) Vol.5, No.3, September 2016, pp. 211 215

${ }^{3}$ Putra, MIS., Pengembangan Perangkat Model Pembelajaran Pemerolehan Konsep (concept attainment) untuk Meningkatkan Hasil Belajar Siswa Pada Pelajaran Fisika di SMP. http://scholar.google.com/scholar?cluster=1785449742839420698\&hl=en\&oi=scholarr. Diakses 30 Mei 2019. 
Pada penelitian ini, peneliti memilih Model Pembelajaran Concept attainment dengan alasan, Model Pembelajaran Concept attainment pada pembelajaran Studi Keislaman ini sangat sesuai dipakai dengan materi-materi yang berkaitan dengan konsep Studi Keislaman. Sehingga peserta didik bisa menikmati pembelajaran yang menyenangkan dan tidak merasa jenuh dalam belajar konsep Studi Keislaman, oleh karena itulah dosen harus mengambil tindakan yang dapat meningkatkan peran aktivitas peserta didik untuk mendukung proses pembelajaran yang menarik dan bermakna dalam kehidupan sehari-hari. ${ }^{4}$

Oleh karena itu, penulis melakukan penelitian untuk mengetahui efektivitas peningkatan hasil belajar peserta didik dalam pembelajaran Studi Keislaman dengan menggunakan Model Pembelajaran Concept attainment. Tujuan penelitian ini adalah untuk mendeskripsikan efektivitas pembelajaran berorientasi Model Concept Attainment ditinjau dari beberapa aspek sebagai berikut:

a. Aktivitas mahasiswa selama mengikuti pembelajaran yang berorientasi menggunakan Model Concept Attainment.

b. Hasil Belajar mahasiswa terhadap kegiatan pembelajaran berorientasi menggunakan Model Concept Attainment.

c. Hambatan atau kendala-kendala yang dihadapi selama proses pembelajaran berorientasi menggunakan Model Concept Attainment.

Manfaat penelitian ini diantaranya adalah:

a. Menjadi acuan bagi dosen/ pendidik dalam menerapkan pembelajaran yang menggunakan Model Concept Attainment pada konsep lain yang relevan.

b. Model Concept Attainment yang digunakan dalam penelitian ini dapat diimplementasikan di Kampus/Institust/Universitas lain yang kondisinya berbeda tetapi dengan penyesuaian-penyesuaian, sehingga dapat meningkatkan Pemerolehan konsep secara terstruktur dan logis mahasiswa.

\section{METODE PENELITIAN}

Jenis penelitian yang dilakukan adalah penelitian eksperimental. Tujuan dari penelitian eksperimental ini untuk menyelidiki kemungkinan saling hubungan sebab akibat dengan cara mengenakan satu atau lebih kelompok eksperimental satu atau lebih kondisi perlakuan dan membandingkan hasilnya dengan satu atau lebih

${ }^{4}$ Putra, MIS., Pembelajaran Fisika dengan Pendekatan Keterampilan Berpikir Kritis Untuk Meningkatkan Hasil Belajar Siswa SMP Unggulan Amanatul Surabaya. PEDAGOGIA: Jurnal Pendidikan 4 (2), 127-134 
kelompok kontrol yang dikenai kondisi perlakuan. ${ }^{5}$ Subjek dalam penelitian adalah Dalam penelitian ini sumber data primernya adalah peserta didik PAI Semester 6 Unipdu Jombang yang memprogram Mata Kuliah PAI.

Penelitian ini menggunakan rancangan "one group pretest-posttest design"6, di mana digunakan satu kelompok subyek. Pertama-tama dilakukan uji awal, lalu dikenakan perlakuan untuk jangka waktu tertentu. Kemudian dilakukan uji akhir. Rancangan penelitian dapat digambarkan sebagai berikut:

\begin{tabular}{ccc}
\multicolumn{3}{c}{ Tabel 1.1. Rancangan Penelitian } \\
\hline Pre test & Perlakuan & Post test \\
\hline $\mathrm{O}_{1}$ & $\mathrm{X}$ & $\mathrm{O}_{2}$ \\
\hline
\end{tabular}

Keterangan tabel:

$\mathrm{O}_{1}=$ uji awal (pretest), untuk mengetahui penguasaan awal siswa terhadap pengetahuan tentang materi sebelum diberikan perlakuan.

$\mathrm{X}=$ Perlakuan, yaitu pelaksanaan pembelajaran dengan menggunakan Model Concept Attainment yang dikembangkan untuk jangka waktu tertentu.

$\mathrm{O}_{2}=$ uji akhir (posttest), untuk mengetahui penguasaan siswa terhadap pengetahuan tentang materi.

Sesuai dengan jenis data yang ingin diperoleh dalam penelitian ini, maka instrumen penelitian yang dikembangkan dan digunakan adalah sebagai berikut:

1. Efektivitas Penerapan Perangkat Pembelajaran

a. Lembar Pengamatan Aktivitas Mahasiswa

Lembar pengamatan Aktivitas ini digunakan untuk mengetahui kemampuan dan aktivitas mahasiswa dalam proses belajar mengajar serta mengamati penguasaan materi tentang pengetahuan konsep mengenai materi ajar sebagai suatu produk. Dalam menyusun instrumen pengamatan yang baik perlu untuk diketahui nilai koefisien reliabilitas.

b. Tes Hasil Belajar

Lembar tes hasil belajar ini digunakan untuk mengukur kemampuan mahasiswa dalam menguasai pengetahuan konsep mengenai PAI sebagai suatu produk. Tes hasil ini digunakan untuk menentukan ketuntasan pencapaian tujuan pembelajaran, ketuntasan individual, ketuntasan klasikal dan sensitivitas tiap butir

${ }^{5}$ Suryabrata, Sumadi, Metodologi Penelitian (Jakarta : PT Raja Grafindo), hal. 17.

${ }^{6}$ Fraenkel, Jack R., 2014. How to Design and Evaluate Research in Education 7th. Mc. Graw Hill Companies, Inc: New York.

${ }^{7}$ Putra, MIS., Implementasi Pembelajaran IPA Terpadu Berbasis Model nested untuk Meningkatkan Respon Belajar Mahasiswa UNIPDU Jombang. TARBIYA ISLAMIA: Jurnal Pendidikan dan Keislaman 7 (1), 93-113 
soal tes hasil belajar. Dalam menyusun instrumen pengamatan yang baik perlu untuk diketahui nilai koefisien reliabilitas, sedangkan dalam menyusun instrumen tes hasil belajar yang baik diperlukan pula analisis validitas dan indeks sensivitas butir soal. $^{8}$

2. Instrumen untuk Mengetahui Keterlaksanaan dan Hambatan dalam Pengembangan Perangkat.

Instrumen ini menggunakan lembar keterlaksanaan RP, dari keterlaksanaan RP dapat diketahui kekurangan-kekurangan dalam pelaksanaan pembelajaran, kemudian dari kekurangan-kekurangan dapat diketahui kendalakendala dalam pembelajaran. Lembar pengamatan hambatan dalam pengembangan perangkat ini ditentukan oleh pengamat secara langsung pada saat KBM sedang berlangsung. Dan hasilnya dicatat pada lembar pengamatan.

Teknik pengumpulan data yang dilakukan menggu nakan teknik sebagai berikut:

1. Observasi/Pengamatan

Observasi/pengamatan dilakukan untuk mengumpulkan data penelitian tentang aktivitas mahasiswa dan keterlaksanaan RPP saat kegiatan pembelajaran berlangsung.

2. Pemberian Tes

Pemberian tes digunakan untuk memperoleh data tentang hasil belajar mahasiswa dan ketuntasan tujuan pembelajaran, ketuntasan individu, klasikal, dan sensivitas butir soal.

3. Pemberian Angket

Pemberian angket dilakukan setelah proses belajar mengajar satu pokok bahasan berakhir. Angket digunakan untuk mengumpulkan informasi data tentang minat dan motivasi mahasiswa terhadap kegiatan pembelajaran menggunakan Model Concept Attainment.

Tujuan analisis data dalam penelitian ini adalah untuk menjawab pertanyaanpertanyaan penelitian yang selanjutnya merumuskan simpulan. Berikut ini data-data penelitian yang akan dianalisis:

1. Analisis Efektivitas Penerapan Perangkat Pembelajaran

a. Analisis Data Aktivitas mahasiswa

${ }^{8}$ Putra, MIS., Pembelajaran., Op.Cit., Hal. 127-134 
Data pengamatan diperoleh dari data yang diberikan oleh 2 pengamat selama proses pembelajaran. Teknik yang digunakan untuk menganalisis aktivitas mahasiswa adalah statistik deskriptif.

b. Analisis Data Tes Hasil Belajar

Analisis data dilakukan dengan tujuan untuk mengukur tingkat ketuntasan hasil belajar mahasiswa dengan menggunakan tes hasil belajar, dan juga menganalisis validitas dan sensitivitas butir soal. Teknik untuk menentukan tingkat ketuntasan tes hasil belajar mahasiswa adalah statistik deskriptif.

2. Hambatan -hambatan yang terjadi selama proses KBM berlangsung

Teknik yang digunakan untuk menganalisis data hambatan-hambatan yang terjadi selama proses KBM adalah deskriptif kualitatif.

\section{PEMBAHASAN}

\section{Konsep Pembelajaran Concept Attainment}

Pembelajaran adalah proses kegiatan belajar mengajar menggunakan metode ilmiah yang tidak hanya ditunjukkan oleh penguasaan dalam konsep maupun teori, tetapi juga perlu penguasaan pengetahuan dalam berpikir ilmiah dan sikap ilmiah. ${ }^{9}$ Bahwa konsep adalah sekelompok stimuli yang mempunyai sifat-sifat yang sama. Stimuli itu dapat berupa benda, kejadian, atau manusia. Pengetahuan dapat diartikan sebagai hierarki aturan-aturan, harus dipelajari dua atau lebih dari dua aturan, sebelum dipelajari aturan yang lebih tinggi tingkatannya. ${ }^{10}$

Model Pembelajaran Concept attainment mula-mula didesain oleh Joyce dan Weil (2003) yang didasarkan hasil riset Jerome Bruner dkk (1956) dengan maksud bukan saja didesain terutama untuk mengembangkan berpikir kritis, tetapi juga untuk menganalisis dan mengembangkan konsep. Kegunaan model mengajar ini adalah: (1) untuk membantu Peserta didik di dalam memahami konsep dengan memperhatikan objek, ide dan kejadian-kejadian; (2) agar Peserta didik lebih efektif di dalam memperoleh konsep dengan cara memahami strategi berpikir ${ }^{11}$.

\footnotetext{
${ }^{9}$ Kustusch, B. M., Assessing The Impact of Representational and Contextual Problem Features. Physical Review Physics Education Research. 12, 010102.

Mason, A. and Singh, C., Surveying Graduate Students' Attitudes and Approaches to Problem Solving. Physical Review Special Topics-Physics Education Research. 6.020124

${ }_{10}$ Putra, MIS., Widodo, W, Jatmiko B. Mundilarto, M., The Development of Science Cps (Collaborative Problem Solving) Learning Model to Improve Future Islamic Elementary School Teachers' Collaborative Problem-Solving Skills and Science Literacy. Unnes Science Education Journal 7 (1) 35-49

11 Joyce, B. dan Weil, M., Models of Teaching. 5th. edition: Pearson Education Inc.
} 
Model Pembelajaran Concept attainment adalah suatu strategi pembelajaran induktif yang didesain untuk membantu para Peserta didik pada semua usia menguatkan pemahaman Peserta didik tentang konsep dan keterampilan berpikir kritis. Model Pembelajaran Concept attainment berasal dari studi tentang proses berpikir. Menurut teori model ini, belajar adalah proses aktif mengenai informasi dan kemudian disusun dan dibentuk dengan cara yang unik oleh setiap individu. Model ini menggunakan contoh-contoh positif dan negatif dalam pembelajaran ${ }^{12}$.

Dalam model ini, pengajar melakukan pengendalian terhadap aktivitas, tetapi dapat dikembangkan menjadi kegiatan dialog bebas dalam fase itu. Peserta didik akan memperkuat konsep yang mereka miliki dengan mentransfer ke permasalahan baru, sehingga cakupan informasi yang mereka dapat akan lebih banyak $^{13}$. Dengan pengorganisasian kegiatan itu diharapkan Peserta didik akan lebih memperlihatkan inisatifnya untuk melakukan proses induktif bersama bertambahnya pengalaman dalam melibatkan diri dalam kegiatan belajar mengajar. Internalisasi merupakan proses menanamkan lebih dalam pemahaman konsep yang telah diperoleh siswa dengan proses pengulangan. Sesuai dengan teori konstruktivis kognitif, yaitu teori tingkat pemrosesan informasi, di mana Peserta didik menangani rangsangan pada tingkat pemrosesan mental yang berbeda dan hanya akan menyimpan informasi yang telah ditangani melalui pemrosesan yang paling sungguh-sungguh dan mendalam ${ }^{14}$

Model Pembelajaran Concept attainment ${ }^{15}$ pada prinsipnya adalah suatu strategi mengajar yang menggunakan data untuk mengajarkan konsep kepada Peserta didik. Dengan model ini Pendidik mengawali pengajaran dengan menyajikan data/contoh, kemudian meminta Peserta didik untuk mengamati data tersebut atas dasar pengamatan ini dibentuk suatu abstraksi.

Prinsip-prinsip pengelolaan yang harus mendapat perhatian bagi pendidik dalam Model Pembelajaran Concept attainment adalah: (1) memberikan dukungan dengan menitikberatkan pada sifat hipotesis dari diskusi-diskusi yang berlangsung; (2) memberikan bantuan kepada Peserta didik dalam mempertimbangkan hipotesis yang satu dari yang lainnya; (3)memusatkan

\footnotetext{
${ }^{12}$ Arends, R. I., Learning to teach; 9th Edition. New York: Mc. Graw -Hill Companies, Inc.

${ }^{13}$ Celik, P., Onder, F., and Silay, I., The Effects of Problem-Based Learning on The Students' Success In Physics Course. Procedia-Social and Behavioral Sciences. Vol. 28 pp. 656-600.

${ }^{14}$ Slavin, E. R., Educational Psychology. Theory and Practice. Boston: Pearson.

${ }^{15}$ Supriyatan, AY., Surahman, E., Suharsono, S., Kemampuan Berpikir Kritis Peserta Didik pada Pembelajaran dengan Model Concept Attainment dan Model Inductive Thinking Materi Pencemaran Lingkungan. Bioedusiana 4 (1) p. 31-37
} 
perhatian peserta didik terhadap contoh-contoh yang spesifik; (4)memberikan bantuan kepada peserta didik dalam mendiskusikan dan menilai stategi berpikir yang mereka pakai. ${ }^{16}$

\section{Langkah-langkah Pembelajaran Concept attainment}

Model Pembelajaran Concept attainment terdiri atas 5 langkah sintaks, yaitu (1) Menyajikan contoh, (2) Menganalisis Hipotesis, (3) Analisis Siklus, (4) Penutup, dan (5) Penerapan.

Tabel 2.1 Sintaks Model Pembelajaran Concept attainment ${ }^{17}$

\begin{tabular}{|c|c|}
\hline Fase & Tingkah Laku Pendidik \\
\hline $\begin{array}{l}\text { Fase-1 } \\
\text { Menyajikan contoh dan } \\
\text { non contoh, } \\
\text { Menyampaikan tujuan } \\
\text { dan menyiapkan kelas }\end{array}$ & $\begin{array}{l}\text { Pendidik menjelaskan tujuan dan prosedur untuk } \\
\text { pelajaran ini dan menyiapkan Peserta didik untuk } \\
\text { siap belajar. } \\
\text { Pendidik menyajikan contoh dan noncontoh } \\
\text { tambahan untuk menguji pemahaman terhadap } \\
\text { konsep. Peserta didik diminta untuk memberikan } \\
\text { contoh dan noncontoh konsep yang lain }\end{array}$ \\
\hline $\begin{array}{l}\text { Fase-2 } \\
\text { Menganalisis Hipotesis }\end{array}$ & $\begin{array}{l}\text { Pendidik mendaftar idea-idea Peserta didik pada } \\
\text { papan tulis dan diberi judul Hipotesis atau "ciri } \\
\text { yang mungkin", dengan menggunakan } \\
\text { menggunakan kata-kata Peserta didik sebanyak } \\
\text { mungkin. } \\
\text { Pendidik mencoba untuk merumuskan beberapa } \\
\text { idea alternatif. dan Pendidik menambah sedikit } \\
\text { contoh lagi (2-3) contoh ke meja. } \\
\text { Pendidik meminta Peserta didik selanjutnya } \\
\text { bekerja berkelompok untuk mendaftar dan } \\
\text { mendiskusikan persamaan ciri pada kelompok } \\
\text { item "YA". Selanjutnya mereka menentukan } \\
\text { konsepnya. } \\
\text { Pendidik meminta Peserta didik kelompok Atribut } \\
\text { "YA" selanjutnya didiskusikan dengan seluruh } \\
\text { kelas dan dibandingkan dengan kelompok } \\
\text { "TIDAK". }\end{array}$ \\
\hline $\begin{array}{l}\text { Fase-3 } \\
\text { Analisis Siklus } \\
\text { (Mengulang Fase I dan } \\
\text { Fase II dengan data } \\
\text { baru) }\end{array}$ & $\begin{array}{l}\text { Pendidik memberikan informasi tambahan untuk } \\
\text { mengeliminasi karakteristik yang tidak diinginkan. } \\
\text { Pendidik melakukan klarifikasi dari respon } \\
\text { Peserta didik, setelah Peserta didik menjelaskan } \\
\text { responnya. } \\
\text { Pendidik mengajukan daftar contoh-contoh untuk } \\
\text { tes }\end{array}$ \\
\hline $\begin{array}{l}\text { Fase-4 } \\
\text { Penutup }\end{array}$ & $\begin{array}{l}\text { Pendidik menanyakan mengenai nama konsep, } \\
\text { definisi, dan atributnya serta contoh lainnnya, } \\
\text { kalau Peserta didik sudah menemukan } \\
\text { karakteristiknya dan konsepnya dan menentukan }\end{array}$ \\
\hline
\end{tabular}

16 Putra, MIS., Op.Cit.

${ }^{17}$ Arends, R. I., Op.Cit. 


\begin{tabular}{|l|l|}
\hline \multicolumn{1}{|c|}{ Fase } & \multicolumn{1}{c|}{ Tingkah Laku Pendidik } \\
\hline $\begin{array}{l}\text { Fase }-5 \\
\text { Penerapan }\end{array}$ & generalisasi. \\
& $\begin{array}{l}\text { Pendidik meminta Peserta didik untuk } \\
\text { menambah contoh atau noncontoh berdasar } \\
\text { pengalaman mereka atau pengetahuan mereka } \\
\text { atau mungkin yang telah mereka lakukan di } \\
\text { rumah. }\end{array}$ \\
\hline
\end{tabular}

(Sumber : Arends. R. L. 2012)

\section{Sistem Sosial}

Sistem sebelum mengajar dengan model pemerolehan konsep, seorang Pendidik memilih konsep, memilih dan mengolah materi ke dalam contoh-contoh dan non contoh, dan mendapatkan contoh-contoh tersebut. Karena sebagian besar buku pelajaran tidak didesain dalam cara yang sesuai dengan dasar konsep belajar seperti yang digambarkan dalam psikologi pendidikan, maka Pendidik harus menyiapkan contoh-contoh, ide-ide pokok dan materi-materi dari teks dan sumber-sumber lain, dan mendesainnya dalam suatu cara di mana atribut-atribut tersebut menjadi jelas. Dalam kegiatan pembelajaran Pendidik harus selalu mengupayakan agar Peserta didik berinisiatif sendiri dalam pembelajarannya. Pendidik harus berperan sebagai perekam, pendorong dan menjabarkan data tambahan.

\section{Prinsip-Prinsip Pengelolaan}

Prinsip dalam model pemerolehan konsep merupakan pola dari kegiatan yang menggambarkan bagaimana seorang Pendidik melihat dan memperlakukan para Peserta didik, termasuk memberikan respon terhadap Peserta didiknya. Prinsip model pemerolehan konsep selama pelajaran berlangsung adalah sebagai berikut:

a. Pendidik harus memiliki sikap mendukung terhadap hipotesis-hipotesis Peserta didik. Pendidik menekankan bahwa Peserta didik harus memiliki dasar dalam membuat hipotesis.

b. Pendidik memberi arahan agar Peserta didik dapat memberikan argumentasinya dalam menguji hipotesis di antara mereka.

c. Pendidik harus memusatkan perhatian Peserta didik pada contoh-contoh yang spesifik. 
d. Pendidik memberikan bantuan kepada Peserta didik dalam mendiskusikan dan menilai strategi berpikir yang mereka pakai. ${ }^{18}$

\section{Sistem Pendukung}

Pembelajaran pemerolehan konsep membutuhkan contoh-contoh dan non contoh untuk disampaikan kepada Peserta didik. Tugas Peserta didik dalam pemerolehan konsep bukanlah untuk menemukan konsep-konsep baru, tetapi untuk mencapai satu konsep yang sebelumnya telah diseleksi oleh Pendidik. Oleh karena itu, untuk menjelaskan konsep-konsep tersebut diperlukan: (1) sarana pendukung yang berupa bahan-bahan dan data yang dipilih dalam bentuk unit-unit yang berfungsi memberikan contoh-contoh; (2) bila Peserta didik sudah dapat berpikir secara komplek, maka Peserta didik dapat berdiskusi dan bekerja sama dalam membuat unit-unit data, seperti yang dilakukan dalam fase kedua saat mencari contoh-contoh lain.

\section{Dampak pengajaran dan dampak pengiring}

Dampak pembelajaran dari model pemerolehan konsep ialah hasil belajar yang dicapai langsung dengan cara mengarahkan para Peserta didik pada tujuan yang diharapkan. Dampak pengiring model pemerolehan konsep ialah hasil belajar lainnya yang dihasilkan oleh suatu proses mengajar belajar, sebagai akibat terciptanya suasana belajar yang dialami langsung oleh para Peserta didik tanpa arahan langsung dari pengajar.

Model pembelajaran pemerolehan konsep merupakan salah satu strategi dari model pembelajaran induktif dengan tujuan membantu Peserta didik segala tingkatan umur untuk mempelajari konsep-konsep dan keterampilan analisis praktis. Konsep sendiri adalah suatu dimensi yang sangat penting dari belajar dan pengembangan kognitif. ${ }^{19}$

Dengan demikian model pembelajaran pemerolehan konsep diharapkan mampu membantu Peserta didik pada segala tingkatan umur untuk mempelajari konsep-konsep dan keterampilan analitis praktis. Dengan kemampuannya tersebut diharapkan suatu konsep mampu dikuasai dengan baik oleh Peserta didik karena sesuai dengan alam berpikir dan bahasa mereka. Model pembelajaran pemerolehan konsep sendiri memiliki beberapa kelebihan.

\footnotetext{
${ }^{18}$ lbid.

${ }^{19}$ Widoko., Model Pembelajaran Konsep (Surabaya: University Press IKIP Surabaya).
} 
Menurut Joyce dan Weil (2003) dampak pengajaran dari model pemerolehan konsep (Concept Attainment) ${ }^{20}$ dan dampak pengiring dapat digambarkan sebagai berikut.

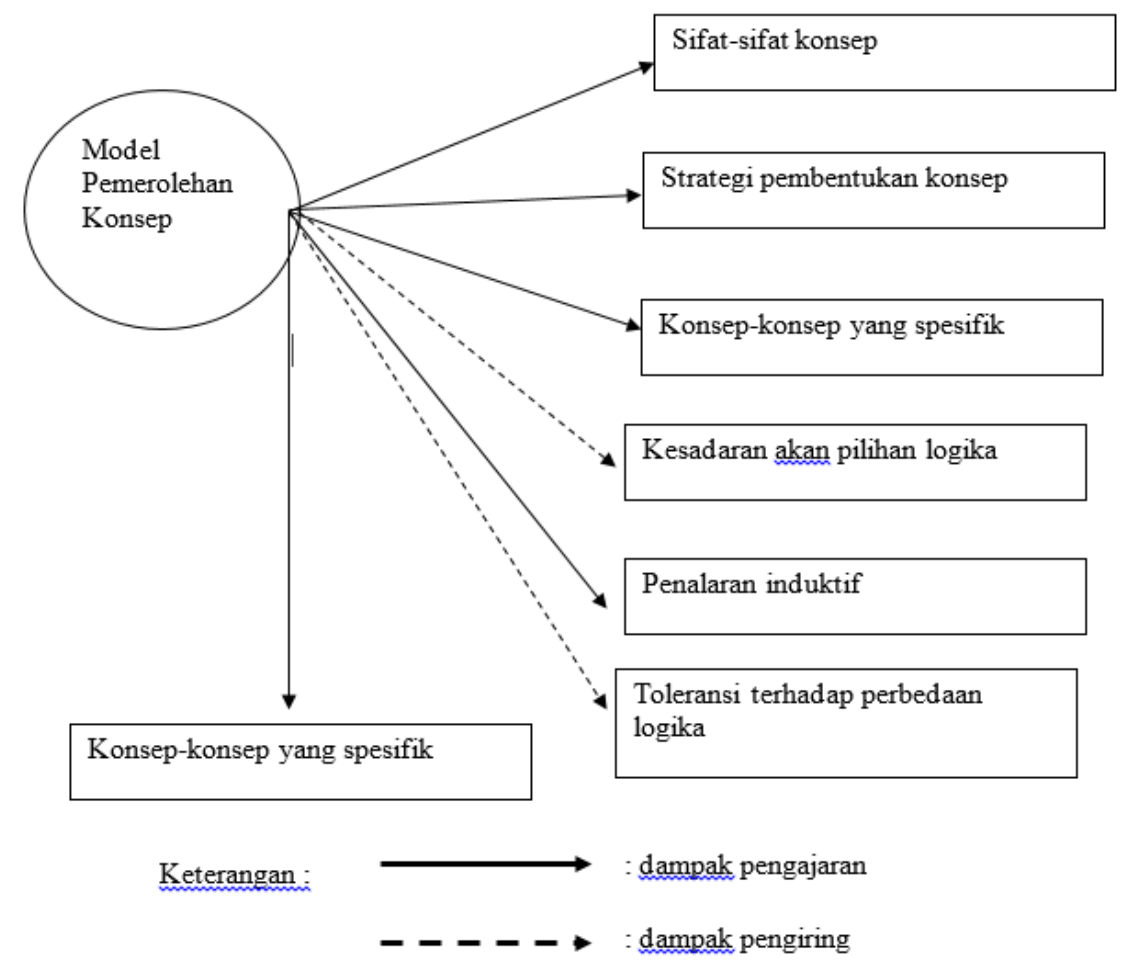

Gambar 2.1. Dampak pengajaran Model Pembelajaran Pemerolehan Konsep (Concept Attainment)

\section{Kelebihan Model Pembelajaran Concept Attainment}

Sebagaimana dalam setiap model pembelajaran tentunya tidak tertutup kemungkinan adanya kekurangan dan kelebihan dari model pembelajaran tersebut. Adapun kelebihan dari Model Pembelajaran Concept Attainment ${ }^{21}$ tersebut adalah:

a. Kelebihan Model Pembelajaran Concept Attainment

1) dapat membuat pembelajaran menjadi lebih Aktif ${ }^{22}$ dan Konkrit

2) Peserta didik lebih mudah memahami pelajaran

3) proses pelajaran lebih menarik

4) Peserta didik dirangsang lebih baik dalam pemrosesan informasi

20 Joyce, B. dan Weil, M., Models of teaching. 5th. edition: Pearson Education Inc.

${ }^{21}$ Widoko., op.cit

${ }^{22}$ Silberman, M., Active Learning : 101 Strategies to Teach Any Subject,. (A. Simon \& Schuster Company Needham Heights, Massachusetts). 
Beberapa hal yang perlu diperhatikan dalam pelaksanaan pembelajaran tersebut ada beberapa langkah yang diambil yakni:

a. Memberi penugasan awal sebelum pembelajaran, dengan cara memberi soal agar dikerjakan di rumah sebelum pembelajaran dilakukan.

b. Memberi tugas mencari fenomena alam yang menurut Peserta didik sesuai dengan materi yang akan diajarkan.

c. Memperbanyak contoh dan non contoh, sebagai jalan untuk memperkaya khasanah pengetahuan Peserta didik tentang materi yang akan dipelajari.

d. Pembimbingan pembelajaran yang aktif selama proses pembelajaran.

Model Pembelajaran Concept Attainment merupakan model yang sangat efisien untuk menyajikan informasi yang teroganisasi dalam berbagai bidang studi. Salah satu keunggulan model pemerolehan konsep ini adalah meningkatkan kemampuan untuk belajar lebih mudah dan lebih efektif. Bahkan dikatakan dari hasil kajian keberlakuan model pemerolehan konsep diperoleh petunjuk yang meyakinkan secara akademis dan praktis, bahwa model pemerolehan konsep dapat digunakan untuk sasaran belajar dari berbagai usia. ${ }^{23}$

Bahwa Model Pembelajaran Concept Attainment dapat digunakan untuk mengembangkan varietas aktivitas kelas, yang juga dapat menghasilkan motivasi Peserta didik. Jadi model ini melibatkan Peserta didik secara aktif dalam menemukan konsep. Dengan menggunakan fakta, data dan contoh untuk mendapatkan konsep, diharapkan akan menimbulkan motivasi Peserta didik untuk mengikuti secara aktif proses belajar mengajar. ${ }^{24}$

Model Pembelajaran Concept Attainment ${ }^{25}$ adalah proses mengidentifikasi dan mendefinisikan konsep dengan jalan menemukan atributnya yang paling esensial sesuai dengan pengertian konsep yang dipelajari. Atribut tersebut harus membedakan contoh konsep itu dengan yang bukan contoh konsep. Oleh karena itu model Pembelajaran Pemerolehan Konsep (Concept Attainment Model) adalah model pembelajaran induktif yang dirancang membantu Peserta didik segala umur untuk belajar konsep sekaligus mempraktikkan keterampilan berpikir analitis. Hasil belajar yang dapat dicapai menggunakan Model Pembelajaran Concept Attainment ini adalah (a) Konsep

${ }^{23}$ Putra, MIS., Op.Cit

${ }^{24}$ Moreno, R. (2010). Educational psichology. New Mecico. John Wiley \& Sons, Inc.

${ }^{25}$ Wenno, I.H., Wattimena, P., Maspaitela, L., Comparative Study between Drill Skill and Concept Attainment Model towards Physics Learning Achievement. International Journal of Evaluation and Research in Education (IJERE) Vol.5, No.3, September 2016, pp. 211-215 
khusus/tertentu, (b) Hakikat konsep, (c) Penalaran logis dan berpikir tingkat tinggi, serta (d) Keterampilan komunikasi. ${ }^{26}$

\section{Hasil dan Pembahasan Penelitian}

Aktivitas mahasiswa dalam Proses Belajar Mengajar diamati dengan menggunakan teknik percentage of agreement dan pengamatan dilakukan oleh 2 orang pengamat. Rekapitulasi hasil perhitungan keterlaksanaan Aktivitas mahasiswa pada kegiatan belajar mengajar RPP 1 dan RPP 2 pada ujicoba dapat dilihat pada Tabel 1.2.

Tabel 1.2 Persentase dan Reliabilitas Instrumen Aktivitas Mahasiswa Selama KBM

\begin{tabular}{|c|c|c|c|c|}
\hline \multirow[t]{2}{*}{ No } & \multirow[t]{2}{*}{ Aspek yang diamati } & \multicolumn{3}{|c|}{$\begin{array}{l}\text { Persentase Aktivitas } \\
\text { Mahasiswa (\%) }\end{array}$} \\
\hline & & RPP I & RPP II & $\begin{array}{l}\text { Rata- } \\
\text { rata }\end{array}$ \\
\hline 1 & $\begin{array}{l}\text { Mengemukakan pendapat/ide- } \\
\text { ide }\end{array}$ & 15.4 & 13.5 & 14.4 \\
\hline 2 & $\begin{array}{l}\text { Memperhatikan } \\
\text { pendemonstrasian oleh dosen }\end{array}$ & 9.3 & 13.1 & 11.2 \\
\hline 3 & $\begin{array}{l}\text { Mengerjakan latihan yang } \\
\text { diberikan }\end{array}$ & 12.9 & 13.5 & 13.2 \\
\hline 4 & $\begin{array}{l}\text { Berdiskusi dengan pasangan } \\
\text { kelompok dalam mengerjakan } \\
\text { latihan }\end{array}$ & 10.0 & 12.9 & 11.4 \\
\hline 5 & $\begin{array}{lr}\text { Memperhatikan } & \text { kelompok } \\
\text { melakukan } & \text { pemodelan } \\
\text { pembelajaran } & \text { MODEL } \\
\text { CONCEPT ATTAINMENT }\end{array}$ & 10.0 & 10.4 & 10.2 \\
\hline 6 & $\begin{array}{llr}\begin{array}{l}\text { Menanggapi } \\
\text { diberikan } \\
\text { lain/dosen }\end{array} & \begin{array}{l}\text { oleh } \\
\text { olehyan yelompok }\end{array} \\
\end{array}$ & 20.4 & 18.8 & 19.6 \\
\hline 7 & $\begin{array}{l}\text { Berdiskusi antara mahasiswa } \\
\text { dan dosen }\end{array}$ & 11.0 & 8.6 & 9.8 \\
\hline 8 & $\begin{array}{l}\text { Menyimpulkan hasil kerja atau } \\
\text { materi pembelajaran }\end{array}$ & 10.3 & 7.6 & 8.9 \\
\hline 9 & $\begin{array}{l}\text { Perilaku yang tidak relevan: } \\
\text { Percakapan yang tidak relevan, } \\
\text { Mengerjakan sesuatu yang tidak } \\
\text { relevan, } \\
\text { Mengganggu teman, } \\
\text { Melamun, dan } \\
\text { Mencari perhatian. }\end{array}$ & 0.9 & 1.6 & 1.3 \\
\hline Jun & lah & 100 & 100.0 & 100.0 \\
\hline Rel & abilitas (\%) & 98.3 & 98.1 & 98.2 \\
\hline
\end{tabular}

${ }^{26}$ Arends, R. I. Op.Cit. 
Bahwa persentase rata-rata aktivitas mahasiswa untuk masing-masing aktivitas mahasiswa meliputi: mengemukakan pendapat, memperhatikan pendemonstrasian oleh dosen, mengerjakan latihan yang diberikan, berdiskusi dengan pasangan dalam mengerjakan latihan, memperhatikan kelompok melakukan pemodelan dalam pembelajaran MODEL CONCEPT ATTAINMENT, menanggapi pertanyaan yang diberikan oleh kelompok lain/dosen, berdiskusi antara mahasiswa dan dosen, menyimpulkan hasil kerja atau materi pembelajaran, perilaku yang tidak relevan: (a) percakapan yang tidak relevan, (b) mengerjakan sesuatu yang tidak relevan, (c) mengganggu teman, (d) melamun, dan (e) mencari perhatian berturut-urut adalah 14,4 $\%, 11,2 \%, 13.2 \%, 11,4 \%, 10,4 \%, 19,6 \%, 9,8 \%, 8,9 \%, 1,3 \%$.

Presentase aktivitas terbesar pada ujicoba ini adalah menanggapi pertanyaan yang diberikan oleh kelompok lain/dosen, yaitu 19,6\%, hal ini disebabkan karena hasil belajar menggunakan perangkat Model Pembelajaran Concept attainment salah satunya adalah keterampilan berkomunikasi, sehingga mengemukakan pendapat memiliki persentase yang paling besar dibandingkan dengan aspek yang lain. Untuk aspek mengemukakan pendapat/ide-ide juga memiliki nilai persentase sebesar $14,4 \%$, hal ini disebabkan mahasiswa menyukai sesuatu yang bersifat baru, karena dalam pembelajaran Model Pembelajaran Concept attainment yang diberikan terdapat halhal yang baru diketahui oleh mahasiswa. Persentase aktivitas terkecil adalah perilaku yang tidak relevan sebesar 1,6\% Lebih jelasnya persentase aktivitas mahasiswa dalam pembelajaran dapat dilihat pada Gambar 1.1 di bawah ini:

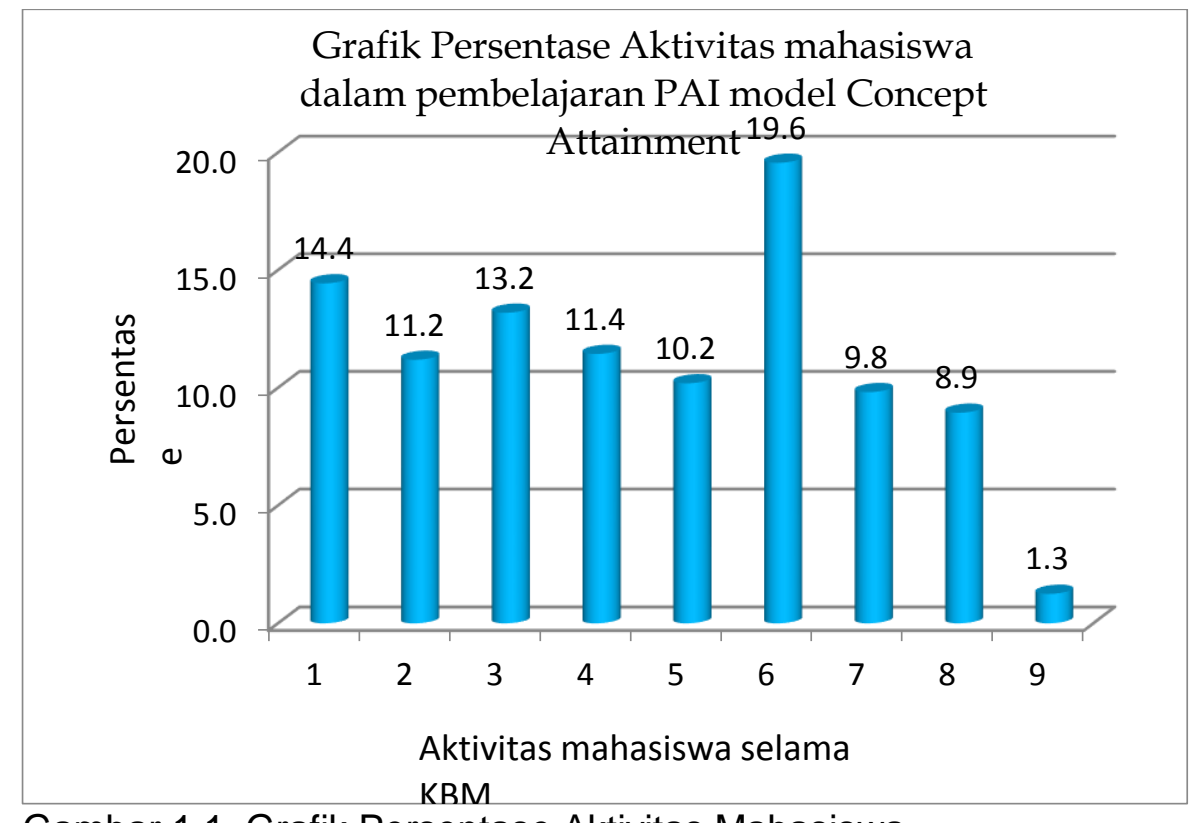

Gambar 1.1. Grafik Persentase Aktivitas Mahasiswa 
Berdasarkan Data Grafik Persentase Aktivitas Mahasiswa pembelajaran PAI dengan Model MODEL CONCEPT ATTAINMENT bahwa Keterampilan yang diharapkan muncul dari mahasiswa selama dan setelah pembelajaran adalah (1) memberikan jawaban atas pertanyaan dengan benar (ketepatan), (2) memberikan jawaban alternatif atas pertanyaan atau masalah (fleksibilitas).

Data di atas menunjukkan bahwa reliabilitas instrumen pengamatan aktivitas mahasiswa untuk masing-masing RPP rata-rata melebihi 75\%.

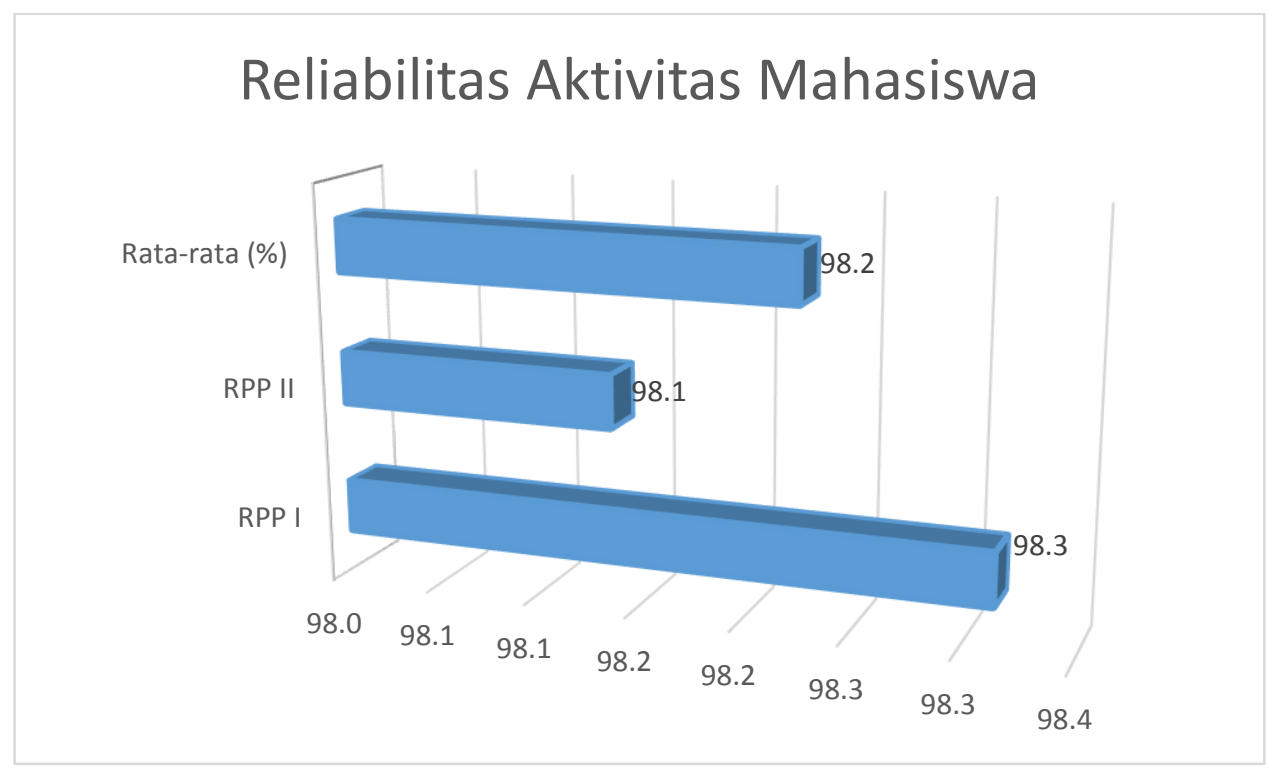

Gambar 1.2. Grafik Persentase Reliabilitas Aktivitas Mahasiswa

Instrumen pengamatan terhadap aktivitas mahasiswa dalam KBM dikatakan reliabel apabila memiliki reliabilitas di atas 75\%. Hasil belajar Mahasiswa dapat mencapai ketuntasan dalam belajar artinya mahasiswa dapat mengikuti pembelajaran PAI dengan model MODEL CONCEPT ATTAINMENT dengan baik, bahwa persentase ketuntasan mahasiswa pada uji awal dan uji akhir meningkat dari $41.8 \%$ menjadi $92.6 \%$. Kendala-kendala yang ditemukan pada penelitian ini, Cara dosen berbicara terkadang terlalu cepat, sehingga dosen perlu mengatur intonasi bicara pada saat pembelajaran.

Pada waktu presentasi hasil kerja kelompok, pembelajaran mahasiswa terlalu banyak menggunakan waktu dalam berdiskusi berpasangan sehingga dosen harus membatasi waktu untuk diskusi berpasangan. Mahasiswa sulit menghubungkan antar konsep dalam pembelajaran pembelajaran PAI dengan menggunakan Model MODEL CONCEPT ATTAINMENT, Sehingga dosen membimbing mahasiswa membuat peta 
konsep pembelajaran PAI dengan menggunakan Model MODEL CONCEPT ATTAINMENT dengan benar.

\section{PENUTUP}

Berdasarkan temuan pada penelitian tentang pembelajaran PAI menggunakan MODEL CONCEPT ATTAINMENT dapat disimpulkan bahwa: ujicoba pembelajaran PAI menggunakan MODEL CONCEPT ATTAINMENT yang dikembangkan dapat dikatakan efektif menunjang hasil belajar dan kegiatan belajar mengajar mahasiswa. Ujicoba pembelajaran efektif menunjang kegiatan belajar mengajar yang didasarkan pada rata-rata pengelolaan pembelajaran berkategori baik. keseluruhan sintaks Model Pembelajaran MODEL CONCEPT ATTAINMENT terlaksana 100\%.

Aktivitas mahasiswa selama kegiatan belajar mengajar menunjukkan bahwa mahasiswa belajar aktif dengan Presentase aktivitas terbesar pada ujicoba ini adalah mengemukakan pendapat yaitu 15,8\%. Respon mahasiswa terhadap Model Pembelajaran MODEL CONCEPT ATTAINMENT adalah kategori baik dan positif. Dengan rincian Perhatian (Attention) mahasiswa terhadap pembelajaran masingmasing 4.12 dengan kategori baik, keterkaitan (Relevance) materi yang dipelajari dengan kebutuhan mahasiswa mempunyai masing-masing 3,73 dengan kategori baik, percaya diri (Confidence)mahasiswa selama mengikuti pembelajaran 3.68 dengan kategori baik, dan kepuasan (Satisfaction) mahasiswa dalam mengikuti pembelajaran 3,87 dengan kategori baik 


\section{DAFTAR PUSTAKA}

Arends, R. I. (2012). Learning to teach; 9th Edition. New York: Mc. Graw -Hill Companies, Inc.

Celik, P., Onder, F., and Silay, I. (2011). The effects of problem-based learning on the students' success in physics course. Procedia-Social and Behavioral Sciences. Vol. 28 pp. 656-600.

Fraenkel, Jack R., 2014. How to design and evaluate research in education 7th. McGraw Hill Companies, Inc: New York.

Joyce, B. dan Weil, M. (2003). Models of teaching. 5th. edition: Pearson Education Inc.

Kustusch, B. M. (2016) Assessing the impact of representational and contextual problem features. Physical Review Physics Education Research. 12, 010102.

Mason, A. and Singh, C. (2010). Surveying graduate students' attitudes and approaches to problem solving. Physical Review Special Topics - Physics Education Research. 6.020124

Moreno, R. (2010). Educational psichology. New Mecico. John Wiley \& Sons, Inc.

Putra, MIS. (2015). Pembelajaran Fisika Dengan Pendekatan Keterampilan Berpikir Kritis Untuk Meningkatkan Hasil Belajar Siswa SMP Unggulan Amanatul Surabaya. PEDAGOGIA: Jurnal Pendidikan 4 (2), 127-134

Putra, M. I. S., Widodo, W. and Jatmiko, B. (2016). The development of guided inquiry science learning materials to improve science literacy skill of prospective mi teacher. Jurnal Pendidikan IPA Indonesia, JPII 5 (1) (2016) 83-93

Putra, MIS. (2017). Pengembangan perangkat model pembelajaran pemerolehan konsep (concept attainment) untuk meningkatkan hasil belajar siswa pada pelajaran Fisika di SMP. http://scholar.google.com/scholar?cluster $=1785449742839420698 \& \mathrm{hl}=$ en\&oi= scholarr. Diakses 30 Mei 2019.

Putra, MIS. (2018). Implementasi Pembelajaran IPA Terpadu Berbasis Model nested untuk Meningkatkan Respon Belajar Mahasiswa UNIPDU Jombang. TARBIYA ISLAMIA: Jurnal Pendidikan dan Keislaman 7 (1), 93-113

Putra, MIS., Widodo, W, Jatmiko B. Mundilarto, M. (2018). The Development Of Science Cps (Collaborative Problem Solving) Learning Model To Improve Future Islamic Elementary School Teachers' Collaborative Problem-Solving Skills And Science Literacy. Unnes Science Education Journal 7 (1) 35-49

Sawtelle, A., Brewe, E., Goertzen, M. R. and Kramer, H. L. (2012) Identifying events that impact self-efficacy in physics learning. Physical Review Special Topics Physics Education Research. 8, 020111 
Shubert, W. C. and Meredith, C. D. (2015). Stimulated recall interviews for describing pragmatic epistemology. Physical Review Physics Education Research. 11, 020138.

Silberman, M.(1996) Active Learning : 101 Strategies to Teach Any Subject, A. Simon \& Schuster Company Needham Heights, Massachusetts.

Slavin, E. R. (2015). Educational psychology. theory and practice. Boston: Pearson.

Supriyatan, AY., Surahman, E., Suharsono, S., (2019). Kemampuan Berpikir Kritis Peserta Didik Pada Pembelajaran Dengan Model Concept Attainment Dan Model Inductive Thinking Materi Pencemaran Lingkungan. Bioedusiana 4 (1) p. 31-37

Suryabrata, Sumadi.(2003). Metodologi Penelitian. Jakarta : PT Raja Grafindo

Teodorescu, E. R., Bennhold, C., Feldman, G., Medsker, L. (2014). Curricular Reforms that Improve Students' Attitudes and Problem-Solving Performance. European Journal of Physics Education. Vol. 5 Issue 1, pp. 15-44.

Wenno, I.H., Wattimena, P., Maspaitela, L. (2016). Comparative Study between Drill Skill and Concept Attainment Model towards Physics Learning Achievement. International Journal of Evaluation and Research in Education (IJERE) Vol.5, No.3, September 2016, pp. 211 215

Widoko .2001. Model Pembelajaran Konsep. Surabaya: University Press IKIP Surabaya. 